\title{
As categorías non verbais. Análise dunha narración oral en galego
}

\author{
Non-Verbal Categories. Analysis of an Galician Oral Narrative
}

\author{
Aitor Rivas \\ Universidade Federal de Viçosa \\ Departamento de Letras \\ aitorrivas@gmail.com
}

[recibido 22/04/2015, aceptado 14/07/2015]

O ser humano é un ser multisensorial. Algunhas veces verbaliza

Ray L. Birdwhistell

\section{RESUMO}

Partindo da concepción da estrutura tripla básica da comunicación humana de Poyatos (1994a, 1994b) e as consecuencias teóricas e analíticas que se derivan da mesma, concibo a comunicación humana como un todo indisolúbel no que a comunicación verbal non se pode separar do comportamento do corpo. Neste artigo analizo as categorías non verbais que se empregan na comunicación oral. $\mathrm{O}$ corpus de estudo consiste nunha narración oral en galego na que, empregando o modelo proposto por Bouvet (2001), individualizo algúns quinemas (unidades mínimas de movemento corporal con significado) que permitan completar a explicación das categorías non verbais con exemplos tirados da gravación.

PALABRAS CHAVE: Comunicación non verbal, Quinema, Oralidade, Categorías non verbais.

\section{RESUMEN}

A partir de la concepción de la estructura triple básica de la comunicación humana de Poyatos (1994a, 1994b) y las implicaciones analíticas y teóricas que se derivan de ella, concibo la comunicación humana como un todo inseparable en el que la comunicación verbal no puede separarse del comportamiento del cuerpo. En este artículo analizo las categorías no verbales utilizadas en la comunicación oral. El corpus de estudio consta de una narración oral en gallego en la que, utilizando el modelo propuesto por Bouvet (2001), individualizo algunos quinemas (unidades mínimas de movimiento corporal con significado) para completar la explicación de las categorías no verbales con ejemplos tomados de la grabación.

PALABRAS CLAVE: Comunicación no verbal, Quinema, Oralidad, Categorías no verbales.

\begin{abstract}
Based on the concept of the triple basic structure of human communication by Poyatos (1994a, 1994b) and on the analytical and theoretical implications that derive from this, the present paper conceives the human communication as an indivisible whole in which verbal communication can not be separated from body behavior. This paper analyzes nonverbal categories used in oral communication. The corpus consists of an oral narration in Galician from which we highlighted certain kinemes (minimum units of body movement with meaning) by using the model proposed by Bouvet (2001), in order to explain the non-verbal categories with examples taken from said recordings.
\end{abstract}

KEYWORDS: Non-verbal Communication, Kinesics, Orality, Non-verbal Categories.

RIVAS, A. (2015): “As categorías non verbais. Análise dunha narración oral en galego”, Madrygal. Revista de Estudios Gallegos (Madr), 18: 111-121 
SUMARIO: 1. Introdución. 2. As categorías non verbais. 2.1. Emblemas. 2.2. Marcadiscursos. 2.3. Marcaespazos. 2.4. Marcatempos. 2.5. Deícticos. 2.6. Pictografías. 2.7. Ecoicos. 2.8. Quinetografías. 2.9. Quinefonografías. 2.10. Ideografías. 2.11. Marcasucesos. 2.12. Identificadores. 2.13. Exteriorizadores. 2.14. Autoadaptadores. 2.15. Alteradaptadores. 2.16. Somatoadaptadores. 2.17. Obxectoadaptadores. 3. Consideracións finais. 4. Referencias bibliográficas.

\section{INTRODUCIÓN}

Nas seguintes páxinas pretendo facer un achegamento ás categorías non verbais e ofrecer algúns exemplos gráficos para complementar a explicación das mesmas. $\mathrm{O}$ corpus de estudo para este artigo consiste nunha gravación dunha narración oral en galego, na que individualizarei e definirei algúns quinemas (unidades mínimas de movemento corporal).

$\mathrm{Na}$ recollida dos datos e na realización da gravación tiven en conta as indicacións que ofrece Duranti (2000: 455-465) para aproveitar mellor as condicións de gravación e as posibilidades técnicas dispoñíbeis.

A nivel teórico adopto a concepción da estrutura tripla básica da comunicación humana de Poyatos (1994a, 1994b) e as consecuencias teóricas e analíticas que se derivan da mesma, concibindo xa que logo, a comunicación humana como un todo indisolúbel no que a verbalidade non se pode separar do que di o corpo. Finalmente, para a análise, emprego o modelo aplicado por Bouvet (2001) no seu estudo do comportamento non verbal nunha contacontos infantil.

Seguindo a metodoloxía de análise empregada en traballos anteriores (Rivas 2009a, 2009b), despois da transcrición da conversa creei unhas fichas de representación que me serviron para individualizar as unidades quinésicas máis representativas.

\section{AS CATEGORÍAS NON VERBAIS}

Dentro dos niveis quinésico e paralingüístico da comunicación inclúense as categorías non verbais. Como explica Poyatos (1994a: 185-223), son un práctico sistema de identificación e definición de condutas interactivas que empregamos para nos comunicar. Estas categorías non se exclúen mutuamente, senón que poden pertencer aos dous grupos ao mesmo tempo. Adscríboas a un grupo ou outro dependendo da función predominante en cada unha delas.

Pasarei, logo, a analizar as principais categorías non verbais utilizadas na comunicación e, nos casos en que sexa posíbel, achegarei exemplos recollidos da gravación da narración oral para ilustralas.

\subsection{EMBLEMAS}

Os emblemas defínense como comportamentos non vocálicos que se poden traducir verbalmente dun xeito directo, é dicir, podemos substituílos por unha palabra. Por exemplo, cando inclinamos a testa cara adiante varias veces, significa para a nosa comunidade de fala (como para moitas outras do mundo) que estamos a afirmar. É dicir, o xesto que traduce e actualiza simbolicamente o "si" afirmativo consiste en mover a testa cara adiante e achegar o queixo contra o pescozo repetidas veces. Aínda cando se trata de sinais arbitrarios, a tradución dun emblema é coñecida por todos os membros dun determinado grupo social e non deixa lugar a dúbidas dentro dese grupo. Os problemas poden vir cando se descoñece a cultura na que se empregan ou o seu significado. Por exemplo, cando viaxamos a países asiáticos notamos que hai comportamentos non verbais que non entendemos e que nos parecen estraños. Isto é debido a que cada grupo ten o seu propio código verbal e tamén pode ter os seus propios repertorios non verbais. Birdwhistell (1970: 156), un dos pioneiros na investigación dos comportamentos non verbais, afirma que "non hai xestos universais. Polo que sabemos, non hai unha soa expresión facial, postura ou posición do corpo que teña o mesmo significado en todas as sociedades"1.

${ }^{1}$ As traducións de todas as citas que aparecen ao longo do artigo son miñas. 
Moitos destes emblemas poden substituír palabras concretas e tamén frases completas (por exemplo, os sinais empregados para insultar coma o dedo pai-de-todos erguido ou o corte de mangas).

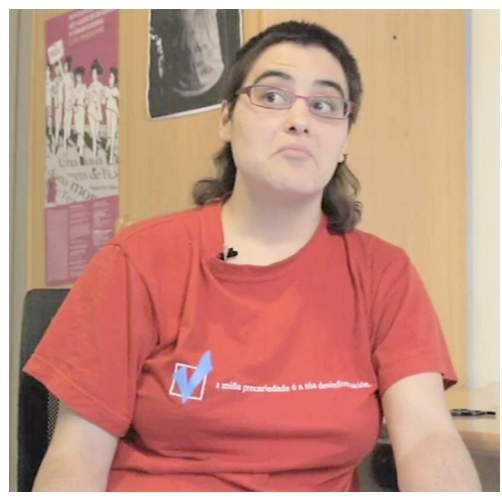

Imaxe 1. Emblema

(...i nunca bebedes algo de zumo?)

Na imaxe 1 pódese observar como a narradora realiza un emblema moi empregado para expresar dúbida, que consiste en arquear as cellas ao mesmo tempo que se moven as comisuras da boca cara abaixo, adiantando lixeiramente o beizo inferior. Considero que este emblema non é exclusivo dos falantes galegos, pois é común a outras culturas, mais estou certo de que podería formar parte dun dicionario de emblemas galego (no caso de existir algún repertorio xestual ${ }^{2}$ da nosa lingua). Paréceme que a elaboración dun traballo deste tipo sería, certamente, moi interesante.

\subsection{MARCADISCURSOS}

Os marcadores gramaticais ou marcadiscursos, termo acuñado por Poyatos (1994a: 189-
190), son condutas fundamentalmente quinésicas -conscientes ou inconscientes- que reforzan a sucesión acústica e gramatical de palabras e frases e virían coincidindo cos signos de puntuación, da representación escrita da fala. Os marcadores son un dos elementos máis importantes da comunicación, pois son os encargados de transmitir os movementos da fala.

\subsubsection{Marcadiscursos quinésicos}

\subsubsection{Marcadores pronominais e adxectivais}

Son movementos corporais que acentúan ou destacan o referente do discurso. Por exemplo, o comportamento para salientar os pronomes ("ti", "el", "ela" etc.). Están sempre presentes, aínda que algunhas veces sexan máis sutís ca outras. Mentres que en inglés adoitan sinalar con movementos de todo o corpo e coa testa, neste caso, para referirse a "vós" (imaxe 2) a narradora galega inclina levemente a testa cara atrás e, cun leve golpe co pescozo fai un movemento co queixo para sinalar cara adiante.

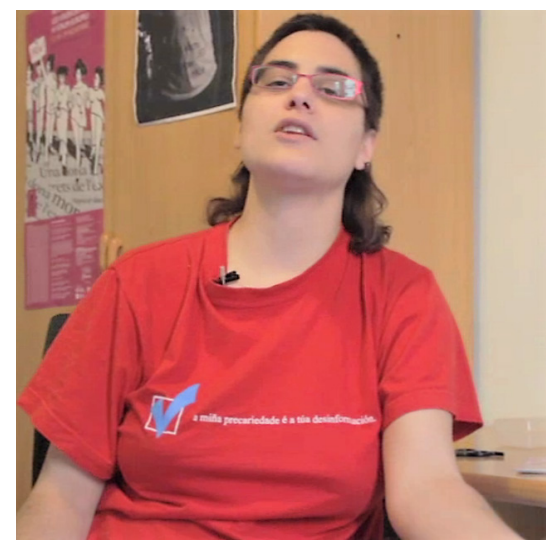

Imaxe 2. Marcador pronominal (vós, que tipo de vida levades?)

${ }^{2}$ Sobre os repertorios de emblemas e xestos existentes noutras culturas e/ou linguas, parécenme especialmente interesantes os de Efron (1941); Ekman e Friesen (1969); Saitz e Cervenka (1972), que estudaron sistematicamente os xestos dos falantes en Colombia e Estados Unidos; Sparhawk (1978), sobre os xestos propios do persa; Poggi e Zomparelli (1987) os asociados ao italiano; o de Kaulfers (1931), unha colección de cincuenta e oito xestos e rituais do español da época; o de Green (1968), orientado ao ensino do español; o dicionario de Indij (2006) de xestos arxentinos; o de Meo Zilio e Mejía (1980-1983), un gran dicionario dos xestos de España e de Hispanoamérica; e o de Payrató (1991), unha tese de doutoramento na que se aproxima aos emblemas da lingua catalá. 
2.2.1.2. Marcadores substantivos, adxectivais, preposicionais e conxuntivos

Por veces teñen índole pictográfica e os nexos de carácter conxuntivo poden ir apoiados con marcadores quinésicos ou de movemento, como os xestos faciais ou os xestos das mans.

\subsubsection{Marcadores acentuais paralingüistico- quinésicos}

Son os que se caracterizan por un ton e volume máis alto, unha articulación máis tensa e unha maior duración silábica e a nivel quinésico por sinalar e arquear as cellas.

\subsubsection{Marcadores de puntuación paralingüis- ticos e quinésicos}

Son os que puntúan unha frase verbal como se fose unha frase escrita. Hai unha correlación entre os marcadores paralingüísticos e quinésicos cos signos de puntuación para intentar representar ou evocar a realidade do discurso, coa súa correspondencia quinésica.

$\mathrm{Na}$ imaxe 3 pódese observar un marcador acentual quinésico (moi común en calquera narración cando o emisor quere destacar e darlle énfase a algúns conceptos ou expresións) no que a narradora xunta o furabolos e o matapiollos da súa man esquerda coma se tivese unha batuta para puntualizar as palabras que pronuncia.

$\mathrm{Na}$ imaxe 4 a narradora afasta a ollada da cámara, apoia o queixo na man e mira cara ao lateral, coa ollada perdida no chan. Isto sérvelle para marcar unha separación entre o que estaba contando e o que vai continuar.

\subsubsection{Marcadores quinésicos de paralinguaxe}

Existen marcadores quinésicos dos trazos paralingüísticos: por exemplo, os ollos moi abertos (marcador quinésico) que poden acompañar o alongamento silábico (marcador paralingüístico).

\subsubsection{Marcadores quinésico-obxectuais}

Existe tamén a manipulación de obxectos mediante o comportamento non verbal, igual que cando puntuamos as palabras, non só con xestos da man, senón engadindo obxectos como o bolígrafo, unha pipa, un vaso coa bebida... con connotacións persoais e sociais.

\subsubsection{Marcadores proxémicos, químico-visuais e dérmicos}

Algunhas mudanzas proxémicas actúan como marcadores para recalcar a palabra (inclinación do corpo, retirarse cara atrás...) ou cambios de postura, que coinciden co final dunha frase e a baixada de ton que reflicten as unidades sintácticas e semánticas. En canto ás reaccións dérmicas, ruborizarse, pórse colorado ou a erección papilar (coiro de pita), poden cumprir as mesmas funcións.

\subsection{MARCAESPAZOS}

Os marcaespazos son a referencia directa a unha dimensión básica nas narracións: o espazo. Serven tanto para sinalar espazos presentes como ausentes. Dentro deles pódense distinguir catro tipos:

a) Os espaciais, que indican o tamaño (non a forma), a distancia e mais a situación.

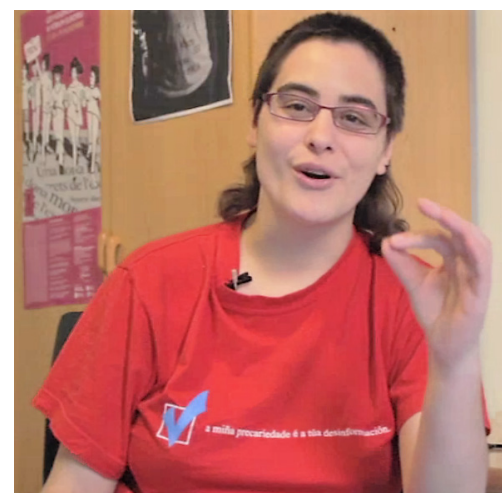

Imaxe 3. Marcador acentual quinésico (Só con tomarvos un cubata)

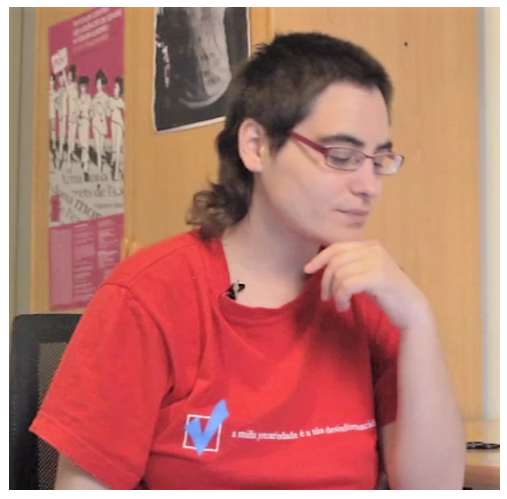

Imaxe 4. Marcador de puntuación (...i nunca bebedes algo de zumo?)

b) Os ilustradores relativos ao tamaño son sempre quinésicos. Por exemplo, separar os brazos do corpo e inchar a barriga para indicar gordura.

c) Os de distancia tamén poden ser quinésicos ou ben paralingüísticos: "bfff!" (que lonxe).

d) Os de situación (que só identifican a alguén ou algo no espazo): "Púxoo aí mesmo, /ai mesmo/". 


\subsection{MARCATEMPOS}

Os marcatempos refírense a diversos puntos do pasado, presente e futuro, á repetición e duración dos acontecementos, e comprenden os adverbios de tempo e as construcións adverbiais e expresións coloquiais que van acompañadas de marcadores temporais. As referencias temporais poden ser ao pasado distante (con move-

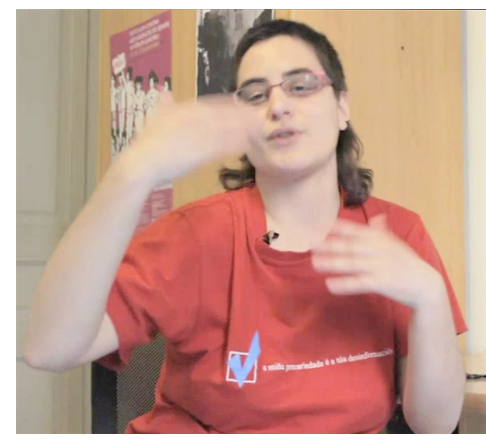

Imaxe 5. Marcatempos

(Despois eles...)

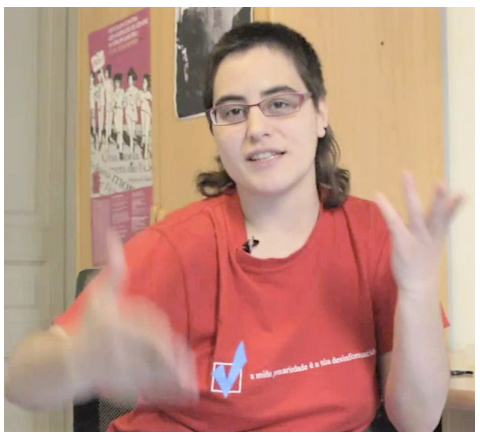

Imaxe 6. Marcatempos (...seguian de marcha) mentos amplos cara atrás ou cara adiante), ao pasado inmediato (con movementos curtos cara atrás), ao presente (con movementos que sinalan o lugar no que se atopa o emisor), ao futuro inmediato (con movementos curtos cara adiante) e ao futuro distante (con xestos similares ao pasado distante pero tamén semicirculares). Os marcadores de recorrencia e duración acompañan a locucións adverbiais e coloquialismos que expresan periodicidade, repetición, lentitude ou rapidez. Estes marcatempos son moi frecuentes nas narracións orais, como o demostran as imaxes 5 e 6. O quinema de marcatempos céntrase no movemento das man dereita (que avanza cara adiante), neste caso acompañado tamén pola outra man, cun xiro completo sobre si mesma e abrindo os dedos lixeiramente cara afora para rematar o movemento.

\subsection{DEÍCTICOS}

Os deícticos son movementos ou sons que indican a situación dunha persoa, obxecto ou lugar no espazo e a situación dun acontecemento no tempo. Poden ser quinésicos (feitos coa man, coa testa, co dedo índice ou co polgar), deícticos de contacto (tocando o interlocutor no antebrazo, no ombreiro ou no xeonllo), deícticos quinésico-paralingüísticos (nos que se relacionan os xestos e movementos coa paralinguaxe) ou deícticos obxectuais (nos que se utilizan obxectos).

Hai tamén deícticos que apuntan cara a referentes ausentes, ben sexan persoas, obxectos ou lugares e outras referencias espaciais a acontecementos no pasado, no futuro ou ao que está a acontecer nese momento. Este é o caso que aparece representado na imaxe 7 , cando a narradora move o seu brazo esquerdo, lixeiramente atrasado, cara a un lateral para se referir aos mariñeiros dos barcos de Colón cando viaxaba a América, nun lugar ausente (e nun tempo pasado).

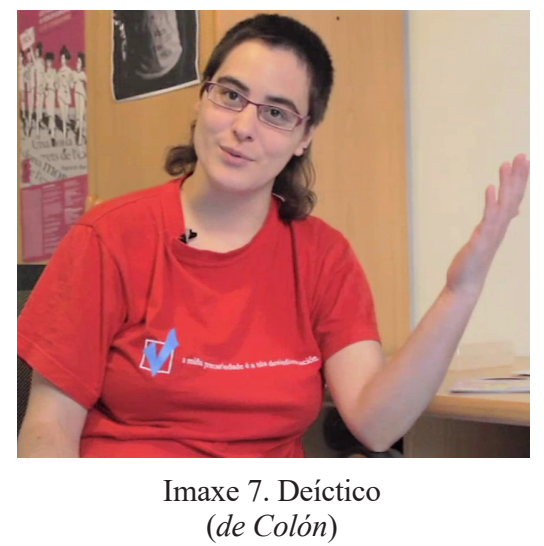

\subsection{PICTOGRAFÍAS}

Son os movementos que serven para debuxar cousas no espazo. As pictografías adoitan ser manuais, acompañan a conversación, e debuxan no aire -ou nunha superficie- a forma, o contorno ou o volume dun referente bidimensional ou tridimensional. A referencia verbal á que acompañan non sempre corresponde exactamente á quinésica, xa que a miúdo iniciamos a pictografía antes de mencionar o referente, o que demostra que as condutas quinésicas moitas veces adiantan o discurso verbal. No caso da narradora que gravei non hai demasiadas pictografías, mais é ben interesante unha delas (imaxe 8), na que debuxa coa súa man dereita a acción, cando un dos personaxes afirma que sente que lle caen os dentes. 


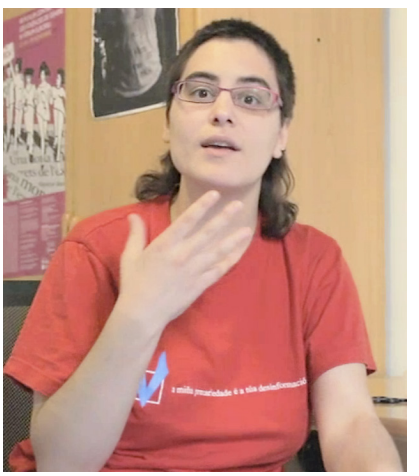

Imaxe 8. Pictografía (parece que me caen os dentes)

\subsection{ECOICOS}

Os ecoicos son as referencias icónicas a modelos acústicos producidos en contacto con obxectos ou co noso propio corpo, ou por medio de emisións vocálicas paralingüísticas. Podemos distinguir os ecoicos vocais (onomatopeas), paralingüísticos (imitacións de animais, de sons da natureza etc.), quinésicos (cando golpeamos contra a mesa para imitar o galope dos cabalos), quinésico-paralingüísticos (cando coinciden comportamentos da quinésica e da paralinguaxe -como no exemplo anterior- pronunciando ao mesmo tempo un "ta-ca-tá-ta-ca-tá-ta-ca-tá").

\subsection{QUINETOGRAFÍAS}

Segundo Ekman e Friesen (1969: 70), as quinetografías son "movementos que representan unha acción corporal ou unha acción física non humana", que só teñen iconicidade quinésica e que non van acompañados de ningún son vocal que imiten. Por exemplo: como corre alguén, como voa un paxaro, como se move unha dorna ao navegar etc.

\subsection{QUINEFONOGRAFÍAS}

As quinefonografias son os movementos que imitan os movementos e o son. Fórmanse con son e movemento producidos polo mesmo tipo de actividade (ao golpear unha superficie para imitar un tambor), con son nunha actividade e son noutra (a imitación vocálica do son dunha locomotora e a quinésica das bielas), ou con

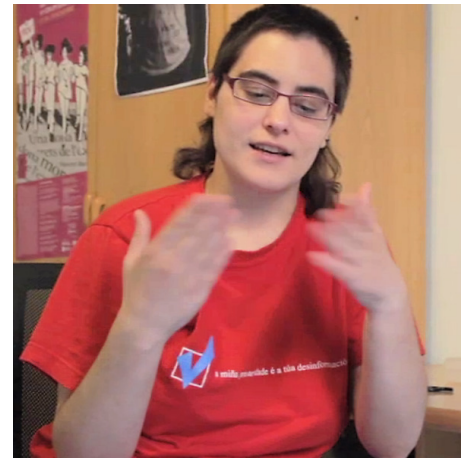

Imaxe 9. Marcasucesos $(s a \ldots)$

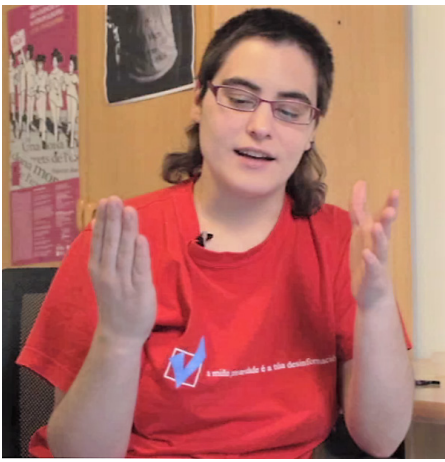

Imaxe 10. Marcasucesos (sa...)

son en dúas actividades e movemento noutra (imitando o galopar dos cabalos con cascos para efectos especiais e deslizando a man por unha superficie).

\subsection{IDEOGRAFÍAS}

Ekman e Friesen (1969: 68) definiron a ideografía como un movemento que "esboza un camiño ou dirección do pensamento, trazando o itinerario dunha viaxe lóxica", pero en realidade pode ser un movemento acompañado de son paralingüístico ou viceversa. Non ilustran o que se di, senón que funcionan por si soas, como emblemas. Por exemplo: cando estamos a pensar nun baile e comezamos a danzar.

\subsection{MARCASUCESOS}

Un marcasucesos, xeralmente de máis duración ca as ideografías, é unha actividade quinésica ou quinésico-paralingüística que traza o acontecer do suceso que se describe. A diferenza das ideografías, o referente descríbese tamén con palabras. A iconicidade aparece soamente cando a ideografía se combina con outra categoría. Por exemplo cando dicimos: "O xantar (acariñando a barriga) foi magnífico".

Nas imaxes 9 e 10 obsérvase un fenómeno moi común: a narradora adiántase ao discurso verbal indicando quinesicamente o que vai acontecer. Neste caso ela está narrando e parece que vai pronunciar o verbo "saían", mais logo hai unha corrección e di: "e... [sa] e... arreglábanse". É unha mostra máis de que as condutas quinésicas moitas veces adiantan o discurso verbal. 


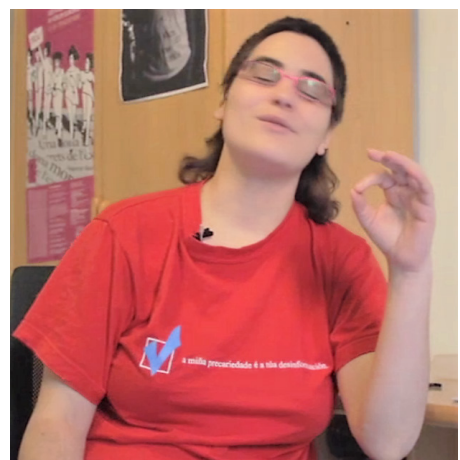

Imaxe 11. Exteriorizador (con...)

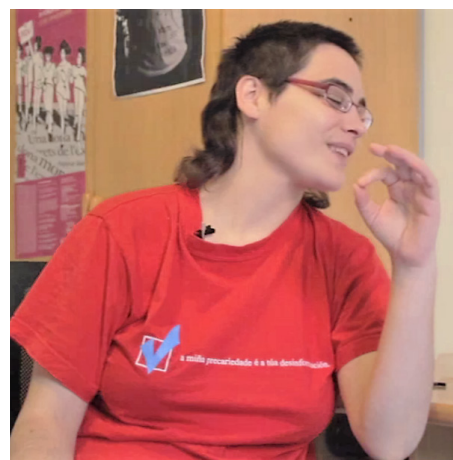

Imaxe 12. Exteriorizador (con...)

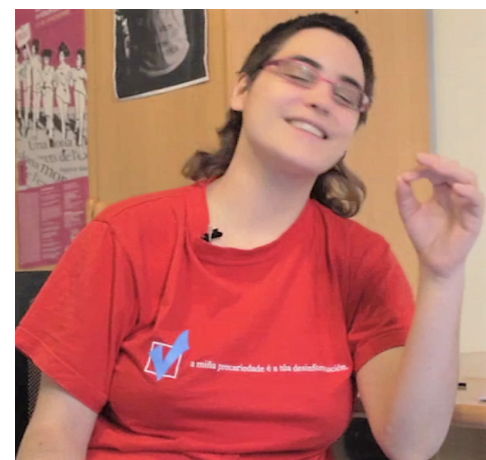

Imaxe 13. Exteriorizador (con...)

\subsection{IDENTIFICADORES}

Os identificadores son condutas quinésicas das que nos axudamos para representarmos conceptos abstractos, cualidades físicas e morais das persoas, animais e cousas e mesmo cualidades de referentes obxectuais e mais ambientais. Estas condutas constrúense mediante a posición da cara e das mans e son moi diferentes dunha cultura a outra (e mesmo dunhas persoas a outras). Un exemplo de identificador sería o puño que amosamos para simbolizar a forza. Algúns identificadores pódense entender como marcadores cando puntualizan as palabras e algúns emblemas teñen a súa orixe como identificadores moi empregados.

\subsection{EXTERIORIZADORES}

Os exteriorizadores sérvennos para mostrar as nosas reaccións fronte á realidade actual, pasada, imaxinada por outras persoas, ao que dixemos, fixemos, estamos a dicir, estamos a facer, diremos ou faremos. Con esta definición englobamos todas aquelas reaccións coas que transmitimos a información (conscientemente ou non). Os exteriorizadores poden expresarse quinesicamente, mais tamén se manifestan mediante a paralinguaxe, a proxémica, unha reacción dérmica, térmica etc. No caso das imaxes 11,12 e 13, o exteriorizador é a resposta da narradora a unha autocorrección no seu discurso. Interrompe o discurso, detén o xesto coa man, move a testa cara a un lateral, apartando a ollada da cámara, e complementa esta secuencia quinésica cun clic paralingüístico, que demostra a súa contrariedade polo erro cometido. Logo retoma o seu discurso verbal.

\subsection{AUTOADAPTADORES}

Defínense como todos aqueles movementos ou posicións onde unhas partes do corpo entran en contacto con outras. Poden durar máis ou menos tempo, pero sempre teñen que ir precedidos e seguidos duns movementos de apertura e de peche que serven para delimitalos. Algunhas funcións que cumpren os autoadaptadores son asumir posturas universais ou culturais, facilitar certas necesidades somáticas, ocultar algunhas destas necesidades, axudar en actividades relacionadas co corpo (como a comida), a limpeza persoal, arranxarse, aliviar ou evitar a dor etc. Algúns exemplos disto serían un corte de manga, facer a burla sacando a lingua, dar palmas, cruzar os brazos ou as pernas, peitearse coas mans, tocar o queixo ou repenar a barba.

$\mathrm{Na}$ imaxe 14 vese como as dúas mans da narradora tocan a cara varias veces, recuperando con ese autoadaptador a frase dun dos personaxes: "non sei que me pasa".

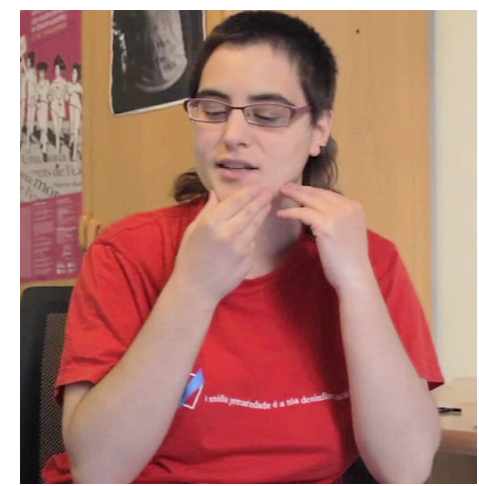

Imaxe 14. Autoadaptador (Non sei que me pasa...) 


\subsection{ALTERADAPTADORES}

A semellanza dos autoadaptadores, definimos os alteradaptadores como aqueles movementos ou posicións cos que contactamos con outras persoas, mais sempre nunha situación interactiva -intencionadamente ou non. Coma as outras categorías, forman parte da estrutura linguaxe-paralinguaxe-quinésica e complementan outros sistemas somáticos e extrasomáticos. As súas funcións son iniciar e rematar encontros sociais, explorar a anatomía doutra persoa, condutas que sirvan como engano, manter a intimidade, actividades propias dos pais e nais cos seus fillos/as, principiar o contacto sexual, agresión, castigo e defensa, protexerse do dano físico, coidar, curar ou aliviar a alguén, lavarse, manexar obxectos relacionados co corpo, expresar afecto e amor, consolar ou animar a alguén, manifestar emocións, simbolizar acordos etc. Exemplos: darlle unha aperta a un amigo/a, darlle un bico, tocalo, acariñalo, collelo da man, cuspir, acompañar a cruzar a rúa a unha persoa cega.

\subsection{SOMATOADAPTADORES}

Os somatoadaptadores son todos aqueles obxectos e substancias máis relacionadas co noso corpo que serven para protexelo, alimentalo e satisfacelo e para modificar a súa aparencia. Son tamén os movementos e posicións condicionados por estes. Segundo os momentos, podemos atopalos en catro estados semióticos ben diferentes: como obxectos e substancias estáticos (ao evocar algunhas condutas dunha persoa só a partir dun obxecto: un perfume, un vestido, unha cadeira etc.); a percepción ou suposición sinestésica de signos (ao imaxinar a maneira de moverse, de andar, de falar e mesmo a paralinguaxe dunha persoa ao ollar un obxecto -por exemplo, un vestido que teña un tacto suave-); a percepción directa dos signos sensíbeis (ao percibirmos estes obxectos mediante máis sentidos ca o da vista, todas as sensacións e imaxes anteriores veñen ao noso maxín e podemos evocar aqueles outros momentos); a realización quinésica e multisensorial (se un perfume cheira ben transpórtanos a outro tempo e espazo e suxire outras sensacións, cando o vestido se move acompañando o corpo -influíndo nas súas maneiras e xestos- ou cando a cadeira está acollendo a unha persoa).

\subsection{OBXECTOADAPTADORES}

Neste grupo están incluídas aquelas condutas que se refiren ao corpo e a outros elementos alleos a el, ou sexa, son aquelas realizacións onde se estabelece unha relación entre o corpo e os obxectos que o rodean. As principais funcións destes obxectoadaptadores son descansar o corpo, facer as tarefas caseiras e laborais, tarefas autoadaptadoras e alteroadaptadoras, recursos conversacionais, actividades comunicativas interactivas, tarefas atléticas ou deportivas, producir música, tratar con animais. Por exemplo: deitarse na cama, sentar nunha cadeira, peitearse, cepillar os dentes, usar lentes, bolígrafos, manexar calquera obxecto, traballar con animais etc. No caso da gravación que analicei, a narradora está sentada nunha cadeira, o que por unha banda pode limitar a realización dalgúns movementos, mais que pola outra ofrece maior comodidade e relaxación para que o seu comportamento quinésico sexa máis natural.

Para alén de todas estas categorías non verbais que veño de presentar, gustaríame facer unha achega máis: os xestos de metaforización da busca. Na imaxe 15 obsérvase un xesto en suspenso que escollín como exemplo da procura do fío condutor do relato da narradora.

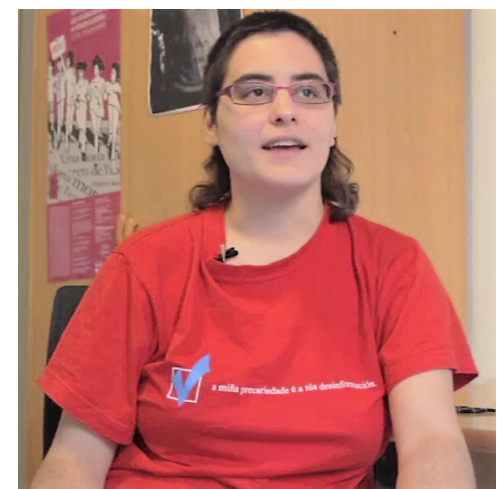

Imaxe 15. Metaforización da busca (eh...)

Hai unha evidente detención do xesto (e do discurso verbal) despois do alongamento de "eh...". Nesta detención do xesto, a narradora mira cara arriba, buscando algo fóra e nese momento hai unha metaforización da busca. Como xa comentei noutra ocasión (Rivas 2009b: 199-200) coa ollada delimítase 
un plano, situado máis lonxe ca o plano da audiencia (inmediatamente anterior a este) e que non pertence á historia, senón á realidade e ao momento da enunciación. Obsérvanse, segundo isto, dous planos diferentes: o primeiro, que se corresponde co espazo onde se moven os personaxes da narración; e o segundo, onde acode a narradora nalgúns momentos coma este para buscar algo máis, cousas que lle faltan e precisa para continuar a narración. É un recurso moi empregado nas narracións orais.

Por último gustaríame incluír unha ligazón ao vídeo que se pode ver en Vimeo (https:// vimeo.com/107201428) e unha transcrición da narración para que sexa máis sinxelo acompañar a historia:

Bueno, vouche contar unha historia que... lle aconteceu a unha xente que coñecín cando vivía en Compostela. O caso é que, bueno, é unha historia de... de dous rapaces, que eles vivían de noite, non? Un... traballaban nunha discoteca... e entonces o que facían era... [pola ma... o que era]... pola noite levantábanse a iso das oito ou nove da noite, almorzaban, e... [sa] e... arreglábanse para ir a traballar de noite á discoteca, estaban na na discoteca hasta as cinco da mañá, despois eles seguían de marcha hasta iso das nove ou dez da mañá, e... ían a un bar a comer o seu bocata de zorza i dispós volvían para a casa i volvían a dormir, e así este ciclo repetíase día tras día todos os días da semana e... menos o... luns, que o luns para o martes descansaban, non? O caso é que... un día nesta vida nocturna (un día) un dos rapaces díxolle ao seu compañeiro:

- Ei, que, noto como que a miña mandíbula se move. Parece que me caen os dentes. Non sei que me pasa... no? Teño esa sensación de que caen os dentes.

E o seu compañeiro lle dixo:

- Jo, eu tamén teño (esta) esta mesma sensación. E téñoa desde hai unha semana, máis ou menos. Ti?

—Eu tamén. Desde hai unha semana. Non sei que pasa.

O caso é que decidiron ir ao médico, no? porque estaban así un pouco inquietos. E o médico, bueno, flipou un pouquiño porque, cando chegou, cando chegaron e lle contaron o que lle estaba pasando e lle fixo, pois unha revisión i tal, eh... o médico díxolle:

-Nunca, nos meus vinte anos de... de traballo como médico vin esta enfermidade. Pensei que xa estaba erradicada. É imposíbel que no século XX, a [no sé...] a principios do século $\mathrm{XXI}$, haxa xente que poida ter, no mundo occidental, esta enfermidade. Non o poido crer. Non o poido crer.

E a verdade é que, claro, estas palabras do médico... puxeron un pouco nerviosos a estes rapaces porque era como...

- Que pasa? Que pasa? Temos unha enfermidade rara. Que...? Que pasa? Que pasa?

E o médico empezoulle a preguntar:

—Bueno, a ver, vós que tipo de vida levades?

-Bueno, non, é que nós é que traballamos de noite. Traballamos nunha discoteca.

—Vale. Que bebedes?

-Bueno... bebemos bastante cocacola con ron e, claro, cubatas i tal.

—Vale: i que comedes?

-Bueno, comemos bastante... bastante... carne, xeralmente un dos nosos platos favoritos é bocata, un bocadillo con zorza.

—I nunca bebedes algo de zumo?

-No, a verdade é que no, só bebemos... claro bebemos moito cubata, a verdade é que zumos non é... non é a nosa bebida favorita.

-Pois mirade, vós o que tedes é escorbuto, principios de escorbuto, que é unha... é esa enfermidade que matou os mariñeiros (da, do...) dos barcos de Colón cando viaxaba a América ou mataba tamén os presos, nas cadeas, cando estaban e... presos, pois por exemplo na época de Franco, na ditadura. Pero o increíble é que hoxe en día, no ano dous mil tres vós teñades os principios de escorbuto... Só con tomarvos un cubata con zumo de... con kas de laranxa teriades o suficiente zumo e suficientes vitaminas como para poder... para que o voso corpo non teña esta enfermidade.

E así foi como estes dous rapaces pasaron de beber cubatas con cocacola... a beber cubatas con fanta limón. 


\section{CONSIDERACIÓNS FINAIS}

Moitos dos movementos analizados demostraron ser excelentes portadores de varias funcións narrativas. Por exemplo, hai movementos significativos do tronco que indican as mudanzas do discurso directo para o indirecto, é dicir, o cambio do papel de narradora para o papel de personaxe da narración.

Outra das características que observei é que, grazas ao movemento do corpo, a narradora transmite boa parte da súa imaxe mental dos personaxes - diferentes posturas coa testa cando se refire ou representa a alguén- dando diferentes informacións sobre o status social, a altura e o comportamento do personaxe da narración. Iso significa que a narradora ten unha imaxe mental dese personaxe e que utiliza a posición da cabeza para situarse nesoutro plano e ofrecer ese contido para os seus ouvintes. Hai outro comportamento quinésico recorrente no que intúo unha utilidade moi produtiva: trátase da corrección lexical. A reparación lexical vai xeralmente precedida ou acompañada por movementos da cabeza, principalmente con acenos laterais, e ás veces pequenos tremores laterais. No caso das correccións este movemento coa testa parece indicar unha reminiscencia pictográfica de querer borrar algo que non é correcto.

Como xa dixen anteriormente (Rivas 2008: 164) penso que é moi importante para os estudos da comunicación non verbal, pero tamén para outros estudos lingüísticos, que a quinésica sexa incorporada (na medida das posibilidades de cada investigación) a calquera análise comunicativa que se leve a cabo.

\section{REFERENCIAS BIBLIOGRÁFICAS}

Birdwhistell, Ray L. (1970): Kinesics and Context: Essays on Body Motion Communication. Philadelphia: University of Pennsylvania Press (https://muse.jhu.edu/books/9780812201284).

Bouvet, Danielle (2001): La dimension corporelle de la parole. Les marques posturo-mimo-gestuelles de la parole, leurs aspects métonumiques et métaphoriques, et leur rôle au cours d'un récit. Paris: Peeters.

Duranti, Alessandro (2000 [1997]): Antropología lingüistica. Madrid: Cambridge University Press.

EFron, David (1941): Gesture and environment. New York: King Crown Press.

Ekman, Paul e Wallace FrIESEN (1969): “The Repertoire of Nonverbal Behavior: Categories, Origins, Usage, and Coding”, Semiotica 1 (1), pp. 49-98.

GreEN, Jerald R. (1968): A Gesture Inventory for the Teaching of Spanish. Filadelfia: Chilton Company.

InDIJ, Guido (2006): Sin palabras. Gestiario argentino. Speechless. A Dictionary of Argentine Gestures. Bos Aires: La marca editora.

Kaulfers, Walter Vincent (1931): “Curiosities in Colloquial Gesture”, Hispania 14 (4), pp. 249264.

Meo Zilio, Giovanni e Silvia Mejía (1980-1983): Diccionario de gestos: España e Hispanoamérica. Bogotá: Instituto Caro y Cuervo.

PAYrató, Lluís (1991): Assaig de dialectologia gestual. Aproximació al repertori d'emblemes del català de Barcelona. Tese de Doutoramento. Barcelona: Universitat.

Poggi, Isabella e Marina Zomparelli (1987): “Ipotesi sul lessico dei gesti”, en P. E. Ricci Bitti (ed.), Comunicazione e gestualitá. Milano: Franco Angeli, pp.134-158.

Poyatos, Fernando (1994a): La comunicación no verbal. I. Cultura, lenguaje y conversación. Madrid: Istmo. 

Istmo.

(1994b): La comunicación no verbal. II. Paralenguaje, kinésica e interacción. Madrid:

RIVAS, Aitor (2008): "Introdución á comunicación non verbal. Panorama de investigación", en E. Fernández Rei e X. L. Regueira (eds.), Perspectivas sobre a oralidade. Santiago de Compostela: Consello da Cultura Galega, pp. 141-167 (https://www.academia.edu/ 6974515/Simposio_oralidade).

(2009a): “《Que dicimos cando non falamos?». O silencio na comunicación”, Madrygal. Revista de Estudios Gallegos 12, pp. 99-107 (http://revistas.ucm.es/index.php/MADR/article/ download/MADR0909110099A/32919).

(2009b): "No ximnasio: análise quinésica do relato dun contacontos", en G. Rei-Doval (ed.), A lingüistica galega desde alén mar. Santiago de Compostela: Asociación Internacional de Estudos Galegos / Instituto da Lingua Galega / Consello da Cultura Galega, pp. 185-211.

Saitz, Robert e Edward Cervenka (1972): Handbook of Gestures: Colombia and the United States. A Haia: Mouton.

Sparhawk, Carol M. (1978): “Contrastive-identificational Features of Persian Gesture”, Semiotica 24 (1-2), pp. 49-86. 